\title{
Immunomodulatory effects of probiotics in different stages of life
}

\author{
Esther Nova $^{1 *}$, Julia Wärnberg ${ }^{1,2}$, Sonia Gómez-Martínez ${ }^{1}$, Ligia E. Díaz ${ }^{1}$, Javier Romeo ${ }^{1}$ and \\ Ascensión Marcos ${ }^{1}$ \\ ${ }^{1}$ Immunonutrition Research Group. Dept. Metabolism and Nutrition, Instituto del Frio. Consejo Superior de Investigaciones \\ Cientificas (CSIC). Madrid, Spain \\ ${ }^{2}$ Unit for Preventive Nutrition. Dept. of Biosciences and Nutrition, Karolinska Institutet. Stockholm, Sweden
}

The immunomodulatory properties of lactic acid bacteria (LAB) and foods containing them (e.g., fermented milks) is a topic currently under investigation. Individuals could potentially benefit from the inclusion of LAB in the diet at different times during the life cycle. One of the most accepted specific uses of probiotic bacteria is the prevention of atopic eczema in infants with family history of the disease who receive the probiotic bacteria early, through supplementation of the gestating mother and orally after birth. Immune enhancing effects have also been suggested to be beneficial in diarrhoea treatment, especially in children infected with rotavirus and in malnourished patients, infants and adolescents, whose capacity to produce IFN- $\gamma$ can be increased after LAB-containing yoghurt intake. Regarding young people and adults, investigations have been conducted exploring the immunomodulation by LAB in subjects under stressful situations, in the prevention of urinary tract infections in fertile women and in the treatment of allergy. However, the beneficial effects of probiotics in these conditions remain controversial and the scientific evidence provided so far is not considered to be conclusive. The elderly population has been the focus of investigations aimed at identifying the capacity of probiotics to counteract the immunosenescence process by increasing phagocytic and natural killer (NK) cell activities and to protect against infection. The mechanisms involved in the different effects attributed to LAB remain to be clarified. Moreover, considering that the immunomodulatory properties are strain-specific, defining the optimal dose of a certain bacteria or combination of bacteria strains and the duration of treatment for a desired effect in a target population group is essential in order to substantiate health claims.

Probiotics: Immunomodulation: Lifespan: Diseases with underlying immune mechanisms

One differential characteristic of some strains of lactic acid bacteria $(\mathrm{LAB})$ used as probiotics compared with other microorganisms is their ability to survive during gastrointestinal transit ${ }^{1}$. This allows them to interact with commensal microbiota and/or intestinal epithelial cells and also with mucosaassociated lymphoid cells ${ }^{2,3}$. The communications between these systems result in the induction or modulation of a number of biological activities that can provide beneficial effects for health ${ }^{4}$. It is accepted that not all LAB strains show probiotic effects and that, with respect to their effects on the host's immune system, a high variability among species and among different strains of the same species is to be expected.

Probiotics are thought to reinforce the intestinal barrier and help maintain normal permeability. On the other hand, LAB have been described binding to the luminal side of the $M$ cells present in the epithelium over the intestinal Peyer's patches and providing antigen transport that facilitates the stimulation of the underlying lymphoid tissue. There is also the possibility that dendritic cells anchored between epithelial cells provide a sampling function of luminal bacteria ${ }^{5}$. Following capture by dendritic cells, the activation of $\operatorname{IgA}$ responses is triggered locally and at distant mucosal sites ${ }^{6}$ which enhances immune exclusion of foreign antigens ${ }^{7}$. In addition, the interaction of probiotic strains with immune cells in the mucosal environment has a principal role in a number of processes directly dependent on the mucosa associated lymphoid tissue (MALT), such as oral tolerance induction, the modulation of cytokine and chemokine release (i.e. induction of regulatory $\mathrm{T}$ cell cytokines) and in general, the regulation of immune responses in the intestinal mucosa which are important in the pathogenesis of inflammatory bowel disease ${ }^{8}$.

Exposure to different challenges during life, either internal or environmental, interferes with the normal development and balance of the healthy gut microbiota. These factors include the early encounter of environmental insults in the newborn, dietary issues such as infant formula feeding, antibiotic treatment, age-related changes in the intestinal physiology and hence in the microbiota, and gastrointestinal diseases and stress. These factors act upon the idiosyncratic immune characteristics of each individual, derived from their genetic background, and drive the development of the immune system and the immune responses triggered by variable stimuli. As the number of environmental insults increases, the damage to the microbiota increases, along with the risk of inflammatory and allergic diseases ${ }^{9}$. Probiotics might help restore gastrointestinal health and immune responses in such circumstances. Physiological and pathological conditions occurring at different stages in life that might benefit from probiotic therapy will be addressed below. 


\section{Gestation and newborns}

The effect of Lactobacillus GG on the prevention of atopic disease has been studied in a group of pregnant women from atopic families ${ }^{10}$. A Lactobacillus rhamnosus GG (LGG) supplement was consumed by the mothers for 4 weeks at the end of their pregnancy and during the breastfeeding period until the child was 3 months old. The potential immunoprotection provided by breast milk was increased as assessed by the concentration of anti-inflammatory transforming growth factor $\beta 2$ (TGF- $\beta 2$ ) in the milk of mothers who received probiotics compared with a placebo group. Moreover, the risk of developing atopic eczema during the first 2 years of life in the infants whose mothers received probiotics was significantly reduced in comparison with that of infants whose mothers received the placebo ( $15 \%$ and $47 \%$, respectively). These results support the protective effect of this probiotic strain against atopic eczema during the first 2 years of life. A more recent study by Kukkonen et al. ${ }^{11}$ was carried out in pregnant women carrying children at high-risk of allergic disease. Mothers received capsules containing LGG, L. rhamnosus LC705, Bifidobacterium breve Bb99 and Propionibacterium freudenreichii ssp. shermanii JS during the 2 to 4 weeks before delivery. Their infants received the same combination of probiotics plus galacto-oligosaccharides or a placebo for 6 months. At 2 years of age the probiotic treatment showed no effect on the cumulative incidence of allergic diseases but significantly prevented eczema and especially atopic eczema (a $34 \%$ relative risk reduction) supporting the inverse association between atopic diseases and colonisation of the gut by probiotics.

The potential use of probiotics in allergic asthma has been investigated in murine models after oral-allergen sensitisation and development of airway inflammation and hyper-reactivity $^{12,13}$. In these models, the protective effect of probiotics has been assessed through an early administration given either to newborns ${ }^{12}$ or perinatally, to the pregnant and lactating mother ${ }^{13}$. Significant effects have been observed in relation to the suppression of inflammation (i.e. reduced eosinophil influx and allergy related cytokines such as IL-5 and IL-10) and airway reactivity with strains such as LGG or Bifidobacterium lactis.

\section{Infants and children}

Immunosuppression is usually secondary to malnutrition and has negative health effects. In an attempt to correct these situations, different studies have been focused on the immunological effects of LAB in malnourished children. The effect of yoghurt (milk fermented with Lactobacillus bulgaricus and Streptococcus thermophilus) was studied in the refeeding of hospitalised malnourished children showing a weight for height value between 70 and $80 \%$, compared with a control group with similar characteristics, receiving the same amount of milk without probiotics in their diet. An increase in serum IFN- $\gamma$ was found in the group consuming yoghurt ${ }^{14}$, which might indicate maintenance of an improved resistance against pathogens.

The efficacy of LAB on the treatment of infantile diarrhoea (especially that due to rotavirus infection) has been assessed in many studies. LGG is one of the most extensively studied strains ${ }^{15-18}$. Two meta-analyses have reported that LGG is associated with moderate clinical benefits in the treatment of acute diarrhoea in children, namely a significant reduction in diarrhoea duration (approximately 1 day), particularly of rotavirus aetiology (about 2 days shorter), and duration of hospitalisation ${ }^{19,20}$. However no significant reductions in the number of stools or total stool volume were found. Sometimes the reduced duration of diarrhoea has been accompanied by an increase in rotavirus-specific IgA-secreting cells ${ }^{16,17}$. Lactobacillus acidophilus might provide similar effects ${ }^{21,22}$ but not all studies have confirmed these results ${ }^{23}$. LGG might also be effective in the prevention of antibiotic associated diarrhoea ${ }^{24,25}$, nosocomial infection diarrhoea ${ }^{26}$ and diarrhoea secondary to malnutrition ${ }^{27}$. Some species of bifidobacteria, such as $B$. infantis and B. bifidum, in combination with lactobacillus have been evaluated in the treatment and prevention of diarrhoea with good results ${ }^{22,28}$.

\section{Adolescents \\ Eating disorders}

Anorexia nervosa (AN), which is a relatively frequent eating disorder in modern society during adolescence, causes patients to present a very undernourished status with peculiar immunological alterations ${ }^{29,30}$. We studied the effect of yoghurt intake ( $375 \mathrm{~g} /$ day) over 10 weeks in a group of AN patients recruited at hospital admission ${ }^{31}$. The findings suggested that the inclusion of yoghurt in the refeeding therapy of AN patients may exert positive effects on the immunological markers related to the nutritional status of these patients, as shown by the higher ratio of $\mathrm{CD} 4^{+}$to $\mathrm{CD}^{+}$cells in the blood of patients consuming yoghurt compared to those consuming milk and by the increased production of IFN- $\gamma$ by PHA-stimulated peripheral blood mononuclear cells (PBMC) both in anorexia nervosa patients and healthy adolescents receiving yoghurt treatment ${ }^{31}$.

\section{Adults}

\section{Healthy youth}

A variety of experimental approaches in vivo and in vitro have been followed in order to test the effects of $L A B$ on cytokine production by immune cells. Firstly, the incubation of PBMC from healthy young adults with Lactobacillus casei, Lactobacillus acidophilus or Bifidobacterium, in vitro, induced an enhancement of IL- 1 , TNF- $\alpha$ and IFN- $\gamma$ production $^{32}$. In addition, a number of in vivo or ex vivo studies have demonstrated that $\mathrm{LAB}$ consumption has a positive effect on IFN production in humans ${ }^{33-35}$ possibly leading to an improved capacity of macrophages and NK cells to kill virus-infected cells or tumour cells. An increase in the 2' 5' adenylate synthetase activity (an enzyme which is induced by IFN- $\gamma$ ) in PBMC has been observed in subjects 24 hours post-consumption of a single dose of yoghurt containing $10^{11}$ bacteria $^{36}$ and also after yoghurt consumption during 15 days compared with milk consumption in a cross-over study ${ }^{32}$. 


\section{Stressful situations in youth}

The effects of psychological and physical stress on health are an increasingly relevant topic of research due to the current lifestyle in our society. Although a certain amount of moderate stress is even considered beneficial, surpassing the threshold has some negative effects on the immune system and causes an impaired resistance to infection. The effect of milk fermented with yoghurt cultures plus Lactobacillus casei DN-114001 (10 $/ \mathrm{ml})$ on the immune system of subjects under academic examination stress was evaluated in a study with university students consuming either $200 \mathrm{ml} /$ day of the fermented product or $200 \mathrm{ml} /$ day of semi-skimmed milk. Although both groups showed increased cortisol and anxiety levels during the exam-taking period, the control group showed a decrease in NK cells that was prevented in the group consuming the fermented milk, who, in addition, showed an increase in numbers of lymphocyte cells ${ }^{37}$. This result could influence susceptibility to infection, which is believed to be higher under stressful conditions.

\section{Infections}

Probiotics are also considered beneficial in the prevention of urinary tract infections (UTIs) in fertile women as observed in a case-control study comparing dietary and lifestyle habits $^{38}$. However, oral ingestion of LGG did not display any clinical efficacy in the protection against UTIs in a controlled intervention trial, which might indicate differences between strains ${ }^{39}$. Regarding microecology of the vagina, in a randomised, double-blind, placebo-controlled study of 64 healthy women, daily intake of $L$. rhamnosus GR-1 and $L$ fermentum RC-14 resulted in significantly less yeast and fewer coliforms in the vagina ${ }^{40}$. Administration of the probiotic organisms even normalised flora in some cases of bacterial vaginosis, making it feasible to study this as an approach to long-term therapy for pregnant women and those susceptible to bacterial vaginosis and urinary tract infections. Adhesion and colonisation of the vaginal epithelium by the strain for days or even weeks may be necessary. Insertion of lactobacilli into the vagina via a pessary or capsule is an effective means of boosting the content of the flora and overcoming some pathogens or reducing their ability to dominate ${ }^{41}$.

\section{Allergies}

The possible utility of probiotics in allergy has received a considerable amount of attention during the last fifteen years. However the evidence is still not strong enough to define any one strain as clearly beneficial in allergy treatment; neither are the mechanisms leading to the observed effects well defined. Remission of nasal allergy symptoms has been described in 42 young subjects and 56 adults consuming $200 \mathrm{~g}$ of yoghurt/day for one year in two separate studies ${ }^{42,43}$. No differences, however, were found in the immunological parameters measured. On the other hand, a study in adults with asthma taking $225 \mathrm{~g}$ of milk fermented with L. acidophilus twice a day for one month showed a tendency towards increased concentrations of IFN- $\gamma$ and a decrease in eosinophil counts ${ }^{44}$. In this last study, however, no improvement was observed in the clinical symptoms or quality of life. A putative capacity of probiotics to direct immune responses towards the production of Th1 profile cytokines could be a possible mechanism to substantiate the use of LAB in the treatment of allergic diseases.

A study with $L$. rhamnosus administered for 3.5 months to young adult patients suffering from birch allergy showed no effect of the probiotic treatment on the allergy symptoms or the use of medication compared to the placebo group ${ }^{45}$. In summary, the evidence for a positive effect of probiotics in allergic diseases is still weak except in the case of atopic eczema.

\section{Phagocytic activity}

One of the immune functions for which more evidence of susceptibility to modulation by probiotic consumption exists is phagocytic activity by peripheral blood leukocytes. It has been documented in healthy volunteers that dietary deprivation of fermented foods for 2 weeks decreases the phagocytic activity of leukocytes ${ }^{46}$. In addition, the consumption of fermented milk containing Lactobacillus acidophilus $\left(7 \times 10^{10} \mathrm{cfu} / \mathrm{d}\right)^{47}$ or Lactobacillus johnsonii La1 $\left(10^{7} \mathrm{cfu} /\right.$ d) ${ }^{48}$ for 3 weeks increased the phagocytic capacity of healthy adults. Likewise, the consumption of Lactobacillus gasseri CECT 5714 and Lactobacillus coryniformis CECT 5711 or yoghurt alone for 2 weeks increased the phagocytic activity of monocytes and neutrophils in healthy subjects ${ }^{49}$. The dose of bacteria consumed daily has been proven important in achieving the desired effect ${ }^{48}$. Other effects of probiotic consumption have also been documented in placebo-controlled intervention trials, such as increases in IgA concentration, increased numbers of $\mathrm{NK}$ cells and activity, and increased oxidative burst capacity of monocytes ${ }^{49,50}$. However, not all the trials have yielded significant results. A probiotic product containing Bifidobacterium lactis and Lactobacillus paracasei assayed at 5 different concentrations, from low $\left(10^{8}\right)$ to high $\left(10^{11}\right)$, in groups of young healthy adults failed to demonstrate any significant modification of phagocytic activity, faecal IgA concentration or production of IFN- $\gamma$ and IL-10 by blood cells ${ }^{51}$. Finally, a combination of probiotic bacteria (Lactobacillus gasseri PA 16/8, Bifidobacterium longum SP 07/3, B. bifidum MF 20/5; $5 \times 10^{7}$ $\mathrm{cfu} / \mathrm{d}$ ) in a dietary vitamin and mineral supplement offered to healthy adults for 3 or 5 months in winter/spring seasons, respectively, significantly decreased the incidence, and also the symptoms, of common cold infections in comparison with the vitamin mineral preparation given to the control group $^{52}$.

\section{Elderly}

Aging is accompanied by a reduction in the functional capacity of all the organs in the body and accordingly the activity of the immune system also declines with age. The senescence of the immune system especially affects cell-mediated immunity with a decrease in lymphocyte proliferation capacity and IL-2 production. However, IgA concentration and antibody titers following immunisation are decreased as well ${ }^{53}$. A decrease has also been observed in the ratio of mature to immature $\mathrm{T}$ lymphocytes ${ }^{54}$ and an increase in proinflammatory cytokine and reactive oxygen species (ROS) production ${ }^{55}$. Perhaps associated with these 
immunological changes, and certainly with other physiological and environmental factors, the bifidobacteria numbers in the gut decrease markedly after 55-60 years of age. Functional foods such as probiotic products may have a particular application in this high-risk group, especially in terms of protection against entero- and urogenital pathogens, and perhaps also in the prevention of several age-related diseases.

Two 3-week intervention trials have shown that Bifidobacterium lactis HN019 supplementation $\left(10^{9}-10^{10} \mathrm{cfu} / \mathrm{d}\right)$ increases the phagocytic capacity of monocytes and polymorphonuclear cells and the NK cell tumoricidal activity in elderly subjects ${ }^{56,57}$. The same bacteria used in a 6 week intervention trial significantly increased the phagocytic activity and the IFN- $\alpha$ production capacity by PBMC in elderly volunteers ${ }^{58}$. Similar results regarding phagocytic and NK cell activities have been also described following the supplementation of middle aged and elderly subjects with Lactobacillus rhamnosus HN001 in similar doses for 3 weeks ${ }^{59}$.

A randomised, controlled pilot study has been carried out to assess the effect of milk fermented with yoghurt cultures and L. casei DN-114001 on the incidence and severity of winter infections (gastrointestinal and respiratory) in elderly people $^{60}$. 360 free-living elderly subjects took part in the study and those in the treatment group consumed two doses of $100 \mathrm{ml}$ fermented product per day for 3 weeks. Although no difference was found in the incidence of winter infections between groups, the duration of all pathologies was significantly lower in the treatment group than in the control group ( $19.5 \%$ reduction in days), as was maximal temperature (mean $38.3 \mathrm{~s} . \mathrm{d} 0.5^{\circ} \mathrm{C}$ treatment group vs. mean 38.5 s.d $0.6^{\circ} \mathrm{C}$ control; $P=0 \cdot 01)$. Further studies with a double-blind placebocontrolled design should be performed for a better assessment of the usefulness of the fermented product in the enhancement of immune defence in the elderly population.

\section{Conclusion}

This review has summarised studies that, at different stages during the lifespan, have used probiotics to provide benefits regarding immune responses and health maintenance (Table 1). There is, however, a need for basic and applied research providing new insight into the nature of the interaction established between the probiotic bacteria and the intestinal mucosa, the mechanisms involved and the active component(s) responsible for the effect, whether bacteria wall components, end products of bacteria metabolism or milk proteins which might be immunologically relevant. In addition, increased knowledge about the specific strains that are the most adequate for each specific purpose, as well as the definition of the recommended dose and duration of supplementation is essential in order to substantiate health claims, and to be able to make specific recommendations to individuals and population groups.

\section{Conflict of interest statement}

AM has had research funding from Danone and Phergal, received consultancy fees from Danone and speaking fees from Danone and Phergal. EN, SGM, LED have received consultancy fees from Danone. JW and JR have no conflicts of interest to declare. All authors co-wrote the manuscript. 


\section{References}

1. Ljungh A \& Wadstrom T (2006) Lactic acid bacteria as probiotics. Curr Issues Intest Microbiol 7, 73-89.

2. Guerin-Danan C, Chabanet C, Pedone C, Popot F, Vaissade P, Bouley C, Szylit O \& Andrieux C (1998) Milk fermented with yogurt cultures and Lactobacillus casei compared with yogurt and gelled milk: influence on intestinal microflora in healthy infants. Am J Clin Nutr 67, 111-117.

3. Vitini E, Alvarez S, Medina M, Medici M, de Budeguer MV \& Perdigon G (2000) Gut mucosal immunostimulation by lactic acid bacteria. Biocell 24, 223-232.

4. Yasui H, Shida K, Matsuzaki T \& Yokokura T (1999) Immunomodulatory function of lactic acid bacteria. Antonie Van Leeuwenhoek 76, 383-389.

5. Corthesy B, Gaskins HR \& Mercenier A (2007) Cross-talk between probiotic bacteria and the host immune system. J Nutr 137, 781S-790S.

6. Macpherson AJ \& Uhr T (2004) Induction of protective IgA by intestinal dendritic cells carrying commensal bacteria. Science 303, 1662-1665.

7. Fang H, Elina T, Heikki A \& Seppo S (2000) Modulation of humoral immune response through probiotic intake. FEMS Immunol Med Microbiol 29, 47-52.

8. Isolauri E (2001) Probiotics in human disease. Am J Clin Nutr 73, $1142 \mathrm{~S}-1146 \mathrm{~S}$

9. Isolauri E, Kirjavainen PV \& Salminen S (2002) Probiotics: a role in the treatment of intestinal infection and inflammation? Gut 50, Suppl 3, III54-III59.

10. Rautava S, Kalliomaki M \& Isolauri E (2002) Probiotics during pregnancy and breast-feeding might confer immunomodulatory protection against atopic disease in the infant. J Allergy Clin Immunol 109, 119-121.

11. Kukkonen K, Savilahti E, Haahtela T, Juntunen-Backman K, Korpela R, Poussa T, Tuure T \& Kuitunen M (2007) Probiotics and prebiotic galacto-oligosaccharides in the prevention of allergic diseases: a randomized, double-blind, placebocontrolled trial. J Allergy Clin Immunol 119, 192-198.

12. Feleszko W, Jaworska J, Rha RD, et al. (2007) Probioticinduced suppression of allergic sensitization and airway inflammation is associated with an increase of T regulatory-dependent mechanisms in a murine model of asthma. Clin Exp Allergy 37, 498-505.

13. Blumer N, Sel S, Virna S, Patrascan CC, Zimmermann S, Herz U, Renz H \& Garn H (2007) Perinatal maternal application of Lactobacillus rhamnosus GG suppresses allergic airway inflammation in mouse offspring. Clin Exp Allergy 37, 348-357.

14. Solis B, Nova E, Gomez S, Samartin S, Mouane N, Lemtouni A, Belaoui H \& Marcos A (2002) The effect of fermented milk on interferon production in malnourished children and in anorexia nervosa patients undergoing nutritional care. Eur J Clin Nutr 56, Suppl 4, S27-S33.

15. Isolauri E, Juntunen M, Rautanen T, Sillanaukee P \& Koivula T (1991) A human Lactobacillus strain (Lactobacillus casei $\mathrm{sp}$ strain GG) promotes recovery from acute diarrhea in children. Pediatrics 88, 90-97.

16. Kaila M, Isolauri E, Soppi E, Virtanen E, Laine S \& Arvilommi H (1992) Enhancement of the circulating antibody secreting cell response in human diarrhea by a human Lactobacillus strain. Pediatr Res 32, 141-144.

17. Majamaa H, Isolauri E, Saxelin M \& Vesikari T (1995) Lactic acid bacteria in the treatment of acute rotavirus gastroenteritis. J Pediatr Gastroenterol Nutr 20, 333-338.

18. Guandalini S, Pensabene L, Zikri MA, et al. (2000) Lactobacillus GG administered in oral rehydration solution to children with acute diarrhea: a multicenter European trial. J Pediatr Gastroenterol Nutr 30, 54-60.
19. Szajewska H, Skorka A, Ruszczynski M \& Gieruszczak-Bialek D (2007) Meta-analysis: Lactobacillus GG for treating acute diarrhoea in children. Aliment Pharmacol Ther 25, 871-881.

20. Huang JS, Bousvaros A, Lee JW, Diaz A \& Davidson EJ (2002) Efficacy of probiotic use in acute diarrhea in children: a metaanalysis. Dig Dis Sci 47, 2625-2634.

21. Simakachorn N, Pichaipat V, Rithipornpaisarn P, Kongkaew C, Tongpradit P \& Varavithya W (2000) Clinical evaluation of the addition of lyophilized, heat-killed Lactobacillus acidophilus LB to oral rehydration therapy in the treatment of acute diarrhea in children. J Pediatr Gastroenterol Nutr 30, 68-72.

22. Lee MC, Lin LH, Hung KL \& Wu HY (2001) Oral bacterial therapy promotes recovery from acute diarrhea in children. Acta Paediatr Taiwan 42, 301-305.

23. Khanna V, Alam S, Malik A \& Malik A (2005) Efficacy of tyndalized Lactobacillus acidophilus in acute diarrhea. Indian J Pediatr 72, 935-938.

24. Arvola T, Laiho K, Torkkeli S, Mykkanen H, Salminen S, Maunula L \& Isolauri E (1999) Prophylactic Lactobacillus GG reduces antibiotic-associated diarrhea in children with respiratory infections: a randomized study. Pediatrics 104, e64.

25. Vanderhoof JA, Whitney DB, Antonson DL, Hanner TL, Lupo JV \& Young RJ (1999) Lactobacillus GG in the prevention of antibiotic-associated diarrhea in children. J Pediatr 135, 564-568.

26. Szajewska H \& Mrukowicz JZ (2001) Probiotics in the treatment and prevention of acute infectious diarrhea in infants and children: a systematic review of published randomized, double-blind, placebo-controlled trials. J Pediatr Gastroenterol Nutr 33, Suppl 2, S17-S25.

27. Oberhelman RA, Gilman RH, Sheen P, Taylor DN, Black RE, Cabrera L, Lescano AG, Meza R \& Madico G (1999) A placebo-controlled trial of Lactobacillus GG to prevent diarrhea in undernourished Peruvian children. J Pediatr 134, 15-20.

28. Saavedra JM, Bauman NA, Oung I, Perman JA \& Yolken RH (1994) Feeding of Bifidobacterium bifidum and Streptococcus thermophilus to infants in hospital for prevention of diarrhoea and shedding of rotavirus. Lancet 344, 1046-1049.

29. Nova E, Gomez-Martinez S, Morande G \& Marcos A (2002) Cytokine production by blood mononuclear cells from inpatients with anorexia nervosa. Br J Nutr 88, 183-188.

30. Marcos A (1997) The immune system in eating disorders: an overview. Nutrition 13, 853-862.

31. Nova E, Toro O, Varela P, Lopez-Vidriero I, Morande G \& Marcos A (2006) Effects of a nutritional intervention with yogurt on lymphocyte subsets and cytokine production capacity in anorexia nervosa patients. Eur J Nutr 45, 225-233.

32. Solis-Pereyra B, Aattouri N \& Lemonnier D (1997) Role of food in the stimulation of cytokine production. Am J Clin Nutr 66, 521S-525S.

33. De Simone C, Vesely R, Bianchi-Salvadori B, et al. (1993) The role of probiotics in modulation of the immune system in man and in animals. Int J Immunother IX, 23-28.

34. Kishi A, Uno K, Matsubara Y, Okuda C \& Kishida T (1996) Effect of the oral administration of Lactobacillus brevis subsp. coagulans on interferon-alpha producing capacity in humans. J Am Coll Nutr 15, 408-412.

35. Halpern G, Vruwink KG, Van de Water J, et al. (1991) Influence of long-term yoghurt consumption in young adults. Int J Immunother 7, 205-210.

36. Solis Pereyra B \& Lemonnier D (1991) Induction of 2'-5' A synthetase activity and interferon in humans by bacteria used in dairy products. Eur Cytokine Netw 2, 137-140.

37. Marcos A, Warnberg J, Nova E, Gomez S, Alvarez A, Alvarez R, Mateos JA \& Cobo JM (2004) The effect of milk fermented by yogurt cultures plus Lactobacillus casei DN-114001 on the immune response of subjects under academic examination stress. Eur J Nutr 43, 381-389. 
38. Kontiokari T, Laitinen J, Jarvi L, Pokka T, Sundqvist K \& Uhari M (2003) Dietary factors protecting women from urinary tract infection. Am J Clin Nutr 77, 600-604.

39. Kontiokari T, Sundqvist K, Nuutinen M, Pokka T, Koskela M \& Uhari M (2001) Randomised trial of cranberry-lingonberry juice and Lactobacillus GG drink for the prevention of urinary tract infections in women. Bmj 322, 1571.

40. Reid G, Charbonneau J, Erb A, et al. (2003) Oral use of Lactobacillus rhamnosus GR-1 and L fermentum RC-14 significantly alters vaginal flora: randomized, placebo-controlled trial in 64 healthy women. FEMS Immunol Med Microbiol 35, 131-134.

41. Reid G \& Bruce AW (2006) Probiotics to prevent urinary tract infections: the rationale and evidence. World J Urol 24, 28-32.

42. Trapp CL, Chang CC \& Halpern GM (1993) The influence of chronic yogurt consumption in population of young and elderly adults. Int J Immunother IX, 53-64.

43. Van de Water J, Keen CL \& Gershwin ME (1999) The influence of chronic yogurt consumption on immunity. J Nutr 129, 1492S-1495S.

44. Wheeler JG, Shema SJ, Bogle ML, Shirrell MA, Burks AW, Pittler A \& Helm RM (1997) Immune and clinical impact of Lactobacillus acidophilus on asthma. Ann Allergy Asthma Immunol 79, 229-233.

45. Helin T, Haahtela S \& Haahtela T (2002) No effect of oral treatment with an intestinal bacterial strain, Lactobacillus rhamnosus (ATCC 53103), on birch-pollen allergy: a placebo-controlled double-blind study. Allergy 57, 243-246.

46. Olivares M, Paz Diaz-Ropero M, Gomez N, Sierra S, LaraVilloslada F, Martin R, Miguel Rodriguez J \& Xaus J (2006) Dietary deprivation of fermented foods causes a fall in innate immune response. Lactic acid bacteria can counteract the immunological effect of this deprivation. J Dairy Res 73, 492-498.

47. Schiffrin EJ, Rochat F, Link-Amster H, Aeschlimann JM \& Donnet-Hughes A (1995) Immunomodulation of human blood cells following the ingestion of lactic acid bacteria. J Dairy Sci 78, 491-497.

48. Donnet-Hughes A, Rochat F, Serrant P, Aeschlimann JM \& Schiffrin EJ (1999) Modulation of nonspecific mechanisms of defense by lactic acid bacteria: effective dose. J Dairy Sci $\mathbf{8 2}$, $863-869$.

49. Olivares M, Diaz-Ropero MP, Gomez N, Lara-Villoslada F, Sierra S, Maldonado JA, Martin R, Rodriguez JM \& Xaus J (2006) The consumption of two new probiotic strains, Lactobacillus gasseri CECT 5714 and Lactobacillus coryniformis
CECT 5711, boosts the immune system of healthy humans. Int Microbiol 9, 47-52.

50. Parra MD, Martinez de Morentin BE, Cobo JM, Mateos A \& Martinez JA (2004) Daily ingestion of fermented milk containing Lactobacillus casei DN114001 improves innatedefense capacity in healthy middle-aged people. $J$ Physiol Biochem 60, 85-91.

51. Christensen HR, Larsen CN, Kaestel P, Rosholm LB, Sternberg C, Michaelsen KF \& Frokiaer H (2006) Immunomodulating potential of supplementation with probiotics: a dose-response study in healthy young adults. FEMS Immunol Med Microbiol 47, 380-390.

52. de Vrese M, Winkler P, Rautenberg P, et al. (2006) Probiotic bacteria reduced duration and severity but not the incidence of common cold episodes in a double blind, randomized, controlled trial. Vaccine 24, 6670-6674.

53. Chandra RK (2002) Nutrition and the immune system from birth to old age. Eur J Clin Nutr 56, Suppl 3, S73-S76.

54. Lesourd B \& Mazari L (1999) Nutrition and immunity in the elderly. Proc Nutr Soc 58, 685-695.

55. Victor VM \& De la Fuente M (2002) N-acetylcysteine improves in vitro the function of macrophages from mice with endotoxininduced oxidative stress. Free Radic Res 36, 33-45.

56. Gill HS, Darragh AJ \& Cross ML (2001) Optimizing immunity and gut function in the elderly. J Nutr Health Aging 5, 80-91.

57. Chiang BL, Sheih YH, Wang LH, Liao CK \& Gill HS (2000) Enhancing immunity by dietary consumption of a probiotic lactic acid bacterium (Bifidobacterium lactis HN019): optimization and definition of cellular immune responses. Eur J Clin Nutr 54, 849-855.

58. Arunachalam K, Gill HS \& Chandra RK (2000) Enhancement of natural immune function by dietary consumption of Bifidobacterium lactis (HN019). Eur J Clin Nutr 54, 263-267.

59. Sheih YH, Chiang BL, Wang LH, Liao CK \& Gill HS (2001) Systemic immunity-enhancing effects in healthy subjects following dietary consumption of the lactic acid bacterium Lactobacillus rhamnosus HN001. J Am Coll Nutr 20, 149-156.

60. Turchet P, Laurenzano M, Auboiron S \& Antoine JM (2003) Effect of fermented milk containing the probiotic Lactobacillus casei DN-114001 on winter infections in free-living elderly subjects: a randomised, controlled pilot study. J Nutr Health Aging 7, 75-77. 